DOI: http://10.4038/kjm.v7i1.7554

\title{
Antecedents of Facebook Updates, and the Role of Personality of Facebook Users in Sri Lanka
}

\author{
Sarathchandra K.S.H. ${ }^{1}$, Nimeshi G.K.S. ${ }^{2}$, Ranwala R.S. ${ }^{3}$, Panditharathne K.M. ${ }^{4}$, Kaushala \\ B.A.H. ${ }^{5}$, Wimalasiri R.K.H.S. ${ }^{6}$, Ranasinghe R.S.L.B. ${ }^{7}$, Mallika M.C.K.H. ${ }^{8}$ \\ Department of Commerce and Financial Management \\ Faculty of Commerce and Management Studies, University of Kelaniya \\ Sri Lanka \\ ${ }^{1}$ sachinthaksh@gmail.com
}

\begin{abstract}
This study is to prove the impact of different motives in updating Facebook status and role of personality in Facebook updates. Therefore, the study is focus to identify the impact of motive namely validation, communication and self-expression on Facebook status updates while it is examining the moderation effect of individual personality on original relationship. As study is based on the Facebook users, population of the study consist of all Facebook users and based on the convenience sampling method researchers have selected 252 Facebook users in Sri Lanka as the sample of the study. Data were collected from the sample using a researcher developed questionnaire. In order to prove hypotheses and make inferences, regression analysis was employed in the study. Moreover, regression analysis proved that there is an impact from validation, communication and self-expression on Facebook status updates. Further, the relationship between validation, communication and self-expression with Facebook status update is moderated by the extraversion and openness to experience. Based on the inferences of the study, it can be concluded that validation, communication and selfexpression act as motives to update Facebook status and the intensity of that motives depend on the personality of an individual.
\end{abstract}

Keywords: Facebook Status Updates, Facebook Usage, Extraversion and Openness to Experience

\section{Introduction}

The establishment and growth of internet technology has paved ways for the displaying of psychological and emotional circumstances especially in the social media platform. It is understood that in light of the increasing popularity and reach of the aforementioned social

${ }^{1}$ https://orcid.org/0000-0002-2215-783X

Kelaniya Journal of Management | 2018 | Vol. 07 | Issue 01 | Page 53 
media platforms and the relevant technology, people may tend to use such platforms with intentions/motives that are highly dependent on the personality traits inherent to each such person or such community. While the term 'Social Media' may refer to an inherently broad category of commercial and non-commercial websites currently active with the aim of connecting people from different geographical bases on a single platform, special focus in this study's perspective will be given to Facebook, the most commonly known Social media network with the highest number of active users as of 2017 (Facebook Statistics Directory, 2017).

Why do people decide to express themselves on Facebook, factually the most active online platform in the digital age remains a question that has not yet been properly addressed with. While it is observable on the surface that people may do so due to various reasons shaped up by their personality traits, the impact of such traits and the motives that guide them in different scenarios have not been academically studied on to a considerable extent. While human communication and expressing their opinions are closely related to mere personality traits, the moderating impact of external factor have neither been assessed, yet remains a significant factor on the outside observations that should properly be researched on. Thus, the main consideration in the study will be given to assess the impact of such motives to the end result, Facebook updates and the study also aims to assess the moderating impact of the personality trait of Extraversion. Field of study for this research is relatively unique and has a significant gap in the existing literature in local context. It is to be noticed that the collaboration between Social Media/Facebook Status Updates and the behavioral circumstances, will be looked at by this study thus providing a basis for future researches as well. The results will be aimed at shedding light on Facebook updates and the impact of personality traits and motives with the special focus given to the moderating impact of the Personality trait of Extraversion. The relevant literature will be explained further on.

\section{Literature Review}

\section{Facebook Status Update}

Social media is one of the most prevalent form among social network sites. These sites specially Facebook has more than one million users and they have created their own profiles using different information like demographic factors, basic information etc. In order to associate with society users, have their friend lists. Facebook is considered as one of the prototypical Social Networking Site (Bergman, Parise, Liseau \& Larsson, 2011; Wilson, Zeithaml, Bitner, \& 
Grem, 2012). Facebook users can use so many features including posting comments and pictures, friend requests, "tagging" others, and creating status updates (Tong, Van Der Heide, Langwell \& Walther, 2008) to interact with others specially their Facebook friends' community.

Among them Status updates represent a new form of one-to-many communication which is extensively used among members of social networking sites (SNS). Carr, Schrock and Dauterman (2012) express status updates as a unique form of communication since they "'afford an asynchronous, publically viewable message, and yet are directed at a specific audience: the user's network' (p. 180). They are usually short texts but can also include pictures or links to videos or online articles. If a user posts an update specially a status update or a picture update, it shows on the profile (wall) of the person who updates that news. After that it will appears her/his Facebook friends' news feed, unless the sender restricted visibility. Other users specially his/her friends can "like" and share the posting or write a comment for that particular update. A linguistic analysis showed that the majority of status updates involves expressive speech acts and rich socio-emotional information (Carr et al., 2012).

Status updates is one of the fastest one-to-many communication method which can be used effortlessly. They can be directed to a large unknown audience and in the Facebook, it is to a large known audience specially all friends on Facebook.

\section{Validation}

Validation is one of motives for spending time on Facebook. (i.e., seeking attention and acceptance) (Bazarova \& Choi, 2014). Neuroticism was related with using Facebook for validation. Certainly, neurotic individuals may use Facebook to look for the attention and support that they lack offline (Ross, Orr, Sisic \& Arseneault, 2009). People are less likely to post on Facebook to seek attention or acceptance (Seidman, 2013). Thoroughness would be positively associated with updating about inoffensive, "safe', topics, which would be mediated by the lower tendency of using Facebook for validation (Seidman, 2013).

H1: There is an impact from use of Facebook for validation to updating Facebook status.

\section{Self-expression}

Self-expression is one of motives for spending time on Facebook (i.e., disclosing personal opinions, stories, and complaints) (Bazarova \& Choi, 2014). The use of Facebook for self- 
expression rather than validation was positively associated with updating about diet/exercise over and above the control variables and traits. Self-expression facilitated the relationship of narcissism with updating about diet/exercise suggesting that narcissists may broadcast their diet and exercise routine to express the personal importance they place on physical appearance (Vazire et al., 2008).

H2: There is an impact from use of Facebook for self-expression to updating Facebook status

\section{Communication}

Communication is one of motives for spending time on Facebook (i.e., corresponding and connecting) (Bazarova \& Choi, 2014). As a social networking website Facebook has modernized by way of communication tool for as a social networking website Facebook has modernized by way of communication tool for maintenance of relationship. According to the Amanda and Joanne (2012), 50\% of Facebook uses out of 500 million uses logging to the Facebook in one specific day. Facebook might be a good means of reaching a real public domain than whatever has originate before Facebook. The absolute fact that millions of people around the world reveals the usefulness of Facebook in communication arena. Facebook is an effective communication method which connect real world communities.

The study carried out by Hampton et al. (2011), stated that, to maintain ongoing communication with close, rather than distant, relations, evidence for depth in online interactions comes from surveys indicating that Facebook is used in the general population. Moreover, it is a very good opportunity for young people to nurture friendship intimacy and social networking sites create those opportunities (Ellison et al., 2007). By using one college sample, more intense Facebook use was associated with higher perceptions of emotional support, in another, $20 \%$ asserted that Myspace brought them closer to their friends. Perhaps having multiple modes of communication, "media multiplicity," enables continual steady contact with close others (Haythornthwaite, 2005), which could increase intimacy.

Another possibility is that only mutual and direct interactions with close others on Facebook are associated with feelings of social support (Vitak et al., 2011), higher life satisfaction, and decreased loneliness (Burke et al., 2010). These findings suggest that, sort of Facebook communication matters for a sense of social support and well-being. We explore this subject in the present study, as a motive of using Facebook and based on the literature researchers developed the following hypothesis; 
H3: There is an impact from use of Facebook for Communication to updating Facebook status.

\section{Extraversion and Facebook Usage}

Extraversion has been defined as "being sociable, gregarious, assertive, talkative, and active (Barrick \& Mount, 1991). One important aspect of extraversion concerns sociability and is revealed in exhibitionism and expression (Barrick \& Mount, 1991). While there may be slight social pressure to present one's self as extraverted, Zywica and Danowski (2008), reported that extraverts believed perceptions of popularity to be paramount on Facebook. Hence, it is likely that extraverts would be more likely to highlight demonstrations of extraversion on social networking Web sites, using the Web sites to enhance their already social lives (Tosun \& Lajunen, 2009).

As Seidman (2013) said, they tend to use Facebook as a tool to communicate and socialize, as reflected in their more frequent use of Facebook (Gosling et al., 2011), larger number of Facebook friends (Amichai-Hamburger \& Vinitzky, 2010), and preference for features of Facebook that allow for active social contribution, such as status updates (Ryan \& Xenos, 2011). We therefore assumed that extraversion would be positively associated with updating about social activities, and that this association would be mediated by extraverts' use of Facebook for communication.

With regard to status updates as a communication feature addressing a larger group of people, it first seems justified to presume that extraverts post more status updates than introverts since the one-to-many communication via status updates offers an ideal place for establishing and maintaining social contacts (Winter et al., 2014).

Hence, we predicted that, Extraversion is related to the relationship of status updates and motives of Facebook status updates. Therefore, here researchers hypothesized that;

H4. The impact of use of Facebook for validation on Facebook status updates is moderated by extraversion.

H5. The impact of use of Facebook for self-expression on Facebook status updates is moderated by extraversion.

H6. The impact of use of Facebook for communication on Facebook status updates is moderated by extraversion. 


\section{Openness to Experience and Facebook Usage}

"Openness to experience (versus closed-mindedness) describes the breadth, depth, originality and complexity of individual's mental and experiential life" (Johan \& Srivastava, 1999, p. 121). People who are high in openness tend to be creative, intellectual, and curious. Openness is positively associated with frequency of social media use (Correa et al., 2010), and with using Facebook for finding and disseminating information, but not for socializing (Hughes et al., 2012).

Openness to Experience is the personality factor most likely to be associated with trying out new methods of communication or using a social network system to seek out new and novel experiences (Butt \& Phillips, 2008). The role of Openness to Experience in Facebook use is less clear, however, Facebook has become a relatively mainstream communication tool for university students (Ellison et al., 2007) and thus may no longer be a "unique" experience.

The study carried out by Ross et al. (2009) found that, heavier users of social networking sites reported higher levels of openness to experience. Furthermore, they said that, high openness to experience is reflected in curiosity and novelty-seeking; low levels are evident in preferences for adhering to convention and established patterns.

We therefore predicted that openness would be positively associated with updating about intellectual topics, and that this association would be mediated by the use of Facebook for sharing information. Moreover, based on the previous literature, the following hypotheses are proposed:

H7. The impact of use of Facebook for validation on Facebook status updates is moderated by Openness to Experience.

H8. The impact of use of Facebook for self-expression on Facebook status updates is moderated by Openness to Experience.

H9. The impact of use of Facebook for communication on Facebook status updates is moderated by Openness to Experience. 


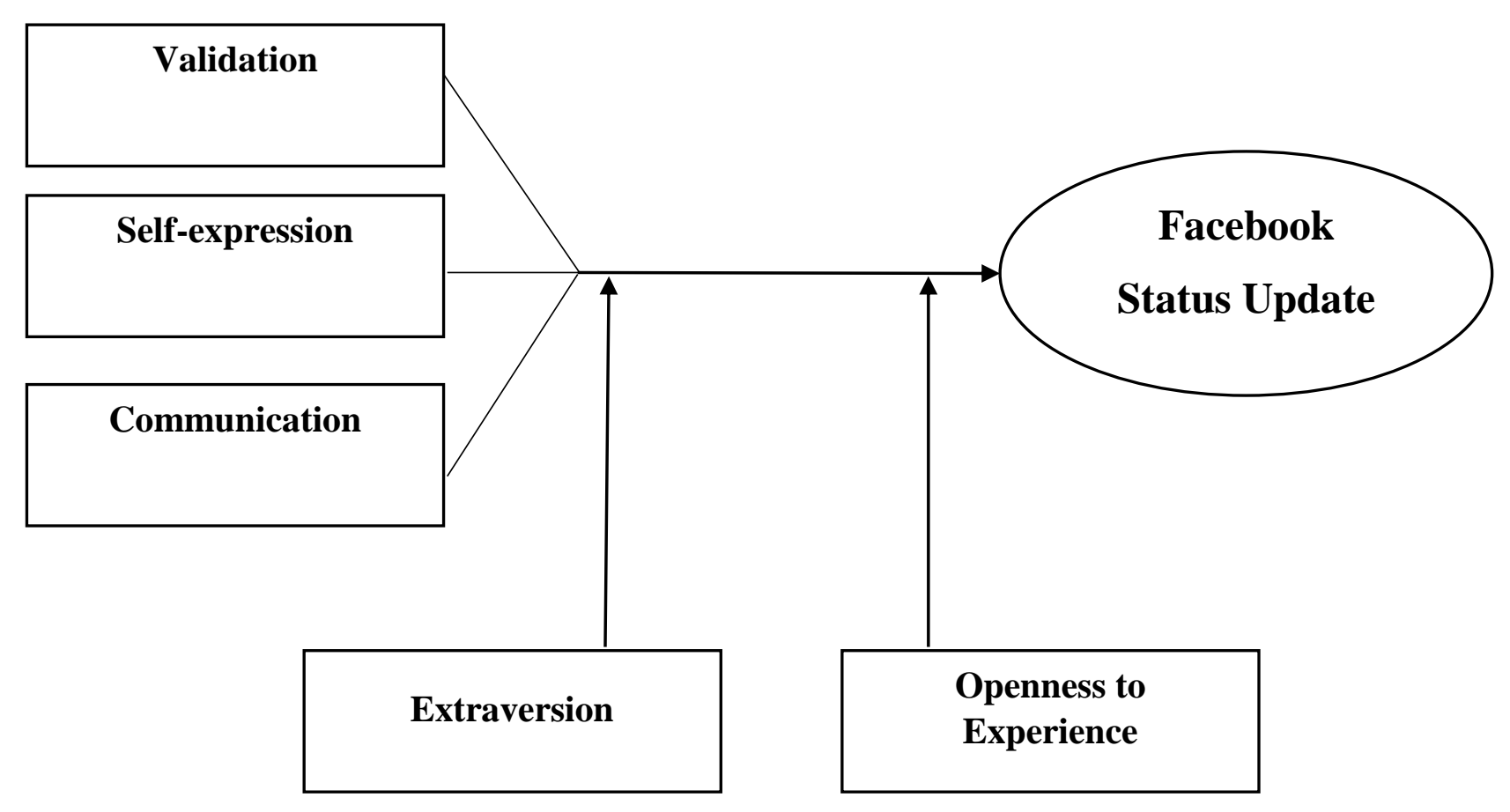

Figure 01: Conceptual Framework

\section{Methodology}

\section{Participants}

The population of the study was all the Facebook users in Sri Lanka. Here according to the convenience sampling method, sample was selected and data was collected from 258 Facebook users residing in Sri Lanka. Out of the 252 respondents 142 (56.4\%) are males and 110 (43.6\%) are females. Among them $84.4 \%$ are between 21-30 years. 56\% of them are employed in full time and $40.1 \%$ of them are having an income between Rs. 10,000 to 50,000. 74.3\% are holders of Bachelor's Degrees. Out of the sample of Facebook users 26.6\% are watching Facebook more than five times per day and only $0.4 \%$ are watching Facebook at once per day.

\section{Measurements}

Data was collected through online questionnaire which consist of four sections, namely demographic information, motives for using Facebook, Facebook updates and personality.

\section{Profiling variables}

Consist with six questions developed by researchers. Questions include gender, income level, education and etc. 


\section{Motives for using Facebook}

Researchers have identified three motives for using Facebook based on the study of (Marshall, Lefringhausen \& Ferenczi, 2015) as validity, self-expression and communication. Each and every motive is considered as independent variables and measures using researchers developed five-point likert scale questions. Five questions to measure the validity, four questions to measure self-expression and six questions to measure communication were used.

\section{Facebook status updates}

Marshall et al. (2015) has identified six categories of topics updating in face book by users as social activities, intellectual themes, achievements, diet/exercise, romantic and children. In this study we also have used the same categories of topics and to measure the constructs, researchers have created a five point likert scale questions starting the statement from "I frequently update ..." to find out which categories of topics users update in Facebook.

\section{Personality}

Personality is used as a moderator in the conceptual framework of this study and out of the Big Five Personality Traits two traits namely extraversion and openness to experience were selected. In order to measure both personality traits, questions developed by John and Pervin (1999) was used and to measure extraversion eight questions and to measure openness to experience ten questions were used.

\section{Results and Findings}

Prior to the main analysis, in order to access the reliability of the data collection instrument reliability analysis was conducted and according to the analysis all the variables depicted a Cronbach alpha level more than 0.8 , which means the questions used were reliable.

Afterward, a multiple regression analysis was done by the researchers to test the impact of validity, self-expression and communication as motives for using Facebook on Facebook status updates. According the below depicted table, it can be identified that the overall model is significant under the 5\% significant level and independent variables together predict the $31 \%$ of dependent variable. Beta values evidence for the variation of Facebook status updates depend on the three motives for using Facebook. Validity, Self-Expression and Communication depicts $35.8 \%, 26.5 \%$ and $15.1 \%$ of variation in Facebook statues updates accordingly. Further, all those variations are significant under the 5\% significant level. Therefore, it is argued that 
validity, self-expression and communication are predictors of Facebook status updates. Based on those results, first there hypothesis were accepted.

Table 1: Summary of Regression Analysis

\begin{tabular}{|l|c|c|c|l|l|}
\hline & ANOVA & \multicolumn{2}{|c|}{ Model Summary } & \multicolumn{2}{c|}{ Unstandardized Coefficients } \\
\hline & Sig & R & $\mathbf{R}^{2}$ & \multicolumn{1}{c|}{ B } & Sig \\
\hline Model & 0.000 & 0.556 & 0.309 & & \\
\hline Validity & & & & 0.358 & 0.000 \\
\hline Self-Expression & & & & 0.265 & 0.006 \\
\hline Communication & & & & 0.151 & 0.021 \\
\hline
\end{tabular}

Subsequently, researchers have performed a multiple regression analysis again with intervening variables of openness to experience and extraversion to assess the moderation effect of openness to experience and extraversion on the original relationship of motives for using Facebook and Facebook status updates.

Firstly, moderation effect of openness to experience was tested. According to the unstandardized coefficient Beta values of motives for using Facebook depicts a positive $23.4 \%$ relationship to the Facebook status updates. However, standardized coefficient Beta value of Motives Openness Inter shows an 11.5\% relationship to Facebook statues updates. Therefore, it can be argued that openness to experience is wakening the relationship between motives for using Facebook and Facebook status updates. Furthermore, that effect is significant under the $5 \%$ significant level and based on that hypothesis four is accepted.

Then, moderation effect of extraversion is tested. As per the unstandardized coefficient Beta values of motives for using Facebook depicts a positive 25.6\% relationship to the Facebook status updates. Though, standardized coefficient Beta value of Motives Extraversion Inter shows a 15.4\% relationship to Facebook statues updates. Hence, it is identified that extraversion is wakening the relationship between motives for using Facebook and Facebook status updates. Moreover, that this effect is significant under the 5\% significant level and based on that hypothesis five is accepted. 
Table 2: Summary of Moderation (Openness to Experience)

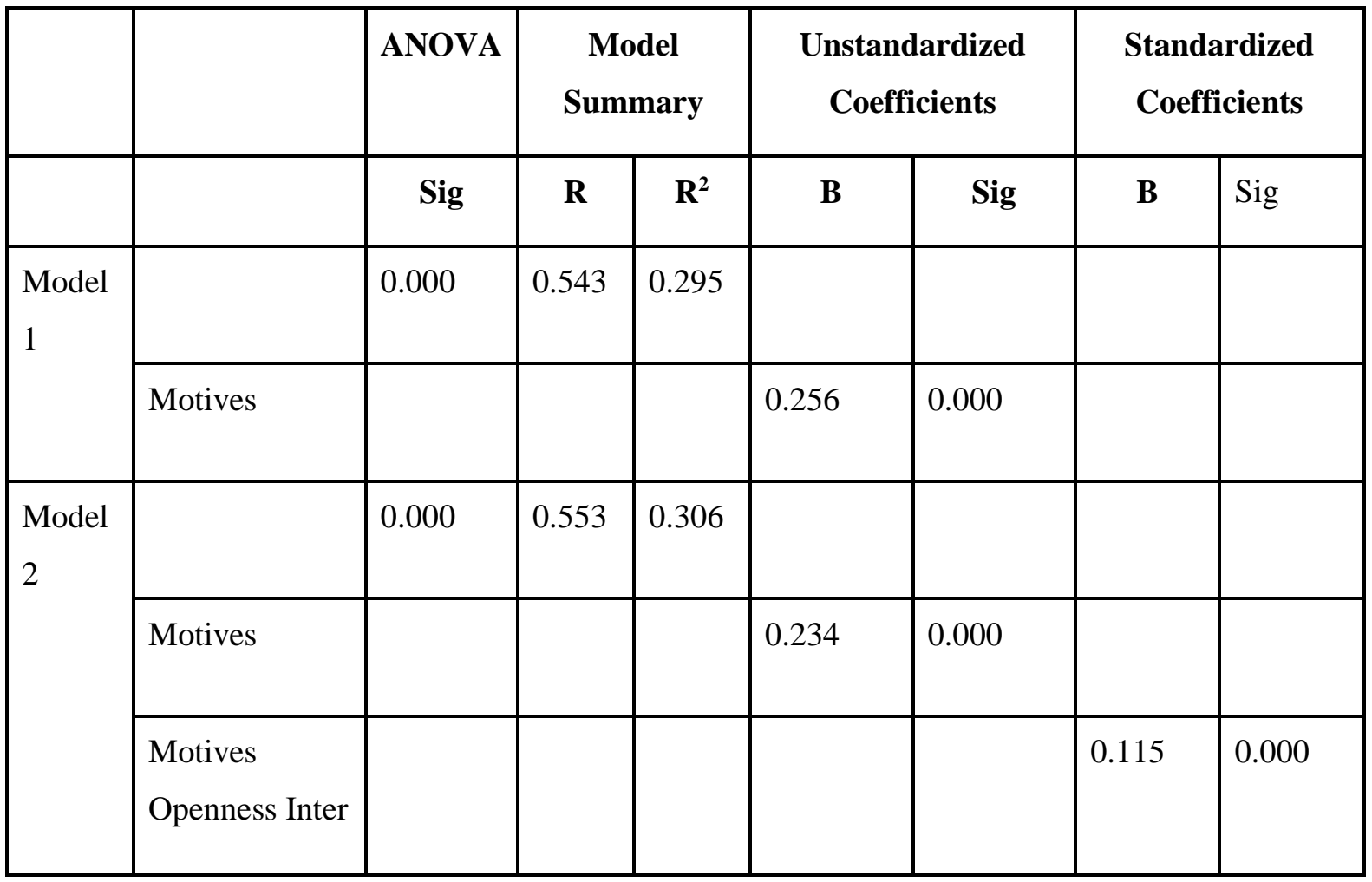

Source: Research Data

Table 3: Summary of Moderation (Extraversion)

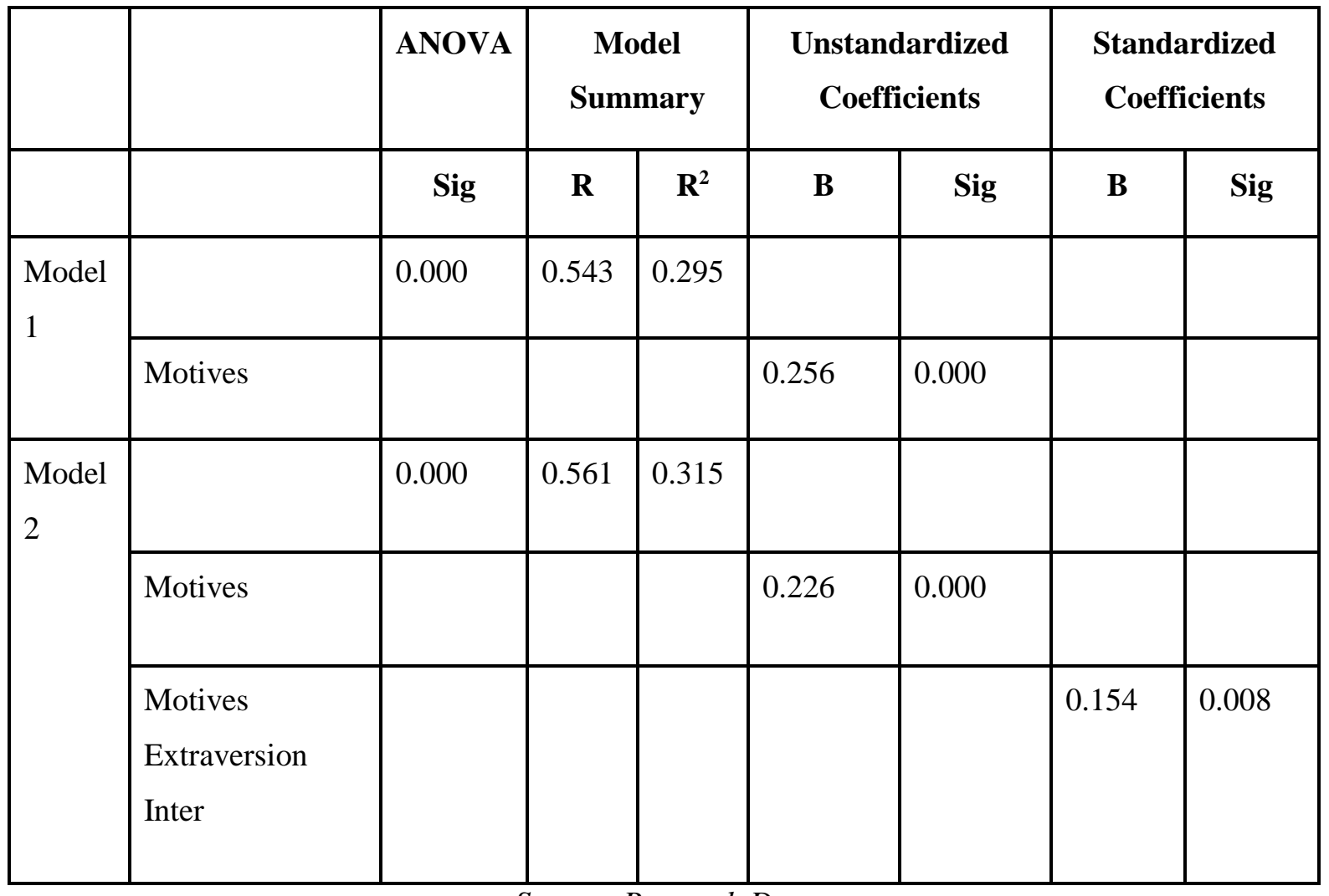

Source: Research Data 
Table 4: Hypothesis Acceptance

\begin{tabular}{|c|c|c|c|c|}
\hline \multirow[t]{3}{*}{ No. } & \multirow[t]{3}{*}{ Hypothesis } & \multirow[t]{3}{*}{ Accepted/Rejected } & \multicolumn{2}{|c|}{ Reason } \\
\hline & & & \multicolumn{2}{|c|}{$\begin{array}{c}\text { Unstandardized } \\
\text { Coefficients }\end{array}$} \\
\hline & & & B & Sig \\
\hline $\mathrm{H} 1$ & $\begin{array}{l}\text { Use of Facebook for Validity is positively } \\
\text { impact updating Facebook status. }\end{array}$ & Accepted & 0.358 & 0.000 \\
\hline $\mathrm{H} 2$ & $\begin{array}{l}\text { Use of Facebook for Self-expression is } \\
\text { positively impact updating Facebook } \\
\text { status. }\end{array}$ & Accepted & 0.265 & 0.006 \\
\hline $\mathrm{H} 3$ & $\begin{array}{l}\text { Use of Facebook for Communication is } \\
\text { positively impact updating Facebook status. }\end{array}$ & Accepted & 0.151 & 0.021 \\
\hline \multirow[t]{2}{*}{$\mathrm{H} 4$} & \multirow{2}{*}{$\begin{array}{l}\text { The relationship between motives for using } \\
\text { Facebook \& Facebook status updates is } \\
\text { moderated by openness to experience. }\end{array}$} & \multirow[t]{2}{*}{ Accepted } & 0.256 & 0.000 \\
\hline & & & 0.115 & 0.000 \\
\hline \multirow[t]{2}{*}{$\mathrm{H} 5$} & \multirow{2}{*}{$\begin{array}{l}\text { The relationship between motives for using } \\
\text { Facebook \& Facebook status updates is } \\
\text { moderated by extraversion. }\end{array}$} & \multirow[t]{2}{*}{ Accepted } & 0.256 & 0.000 \\
\hline & & & 0.154 & 0.008 \\
\hline
\end{tabular}

Source: Research Data

\section{Discussion, Conclusion and Recommendations}

The main contemplation of the study is to assess the impact of motives namely, Selfexpression, validation and communication of using Facebook on Facebook status update. And this study aims to assess the moderating impact of the personality trait of Extraversion and Openness to experience also.

The results showed that all the three motive factors correlated positively with Facebook status update. This sheds light for facilities Human Resource managers on the design and 
implementation of recruitment processes in organizations. And also, they can use these information in shaping up organizational culture. Not only them even psychologists can create theories, come to decisions regarding persons' cognitive styles based on this information. Furthermore, marketing managers can do the product marketing by updating Facebook status according to the target markets' personality and their motives.

The results suggested that each of the three motives - Self-expression, validation and communication - contributed approximately 31 percent of $\mathrm{R}^{2}$ in explaining Facebook status updates. However, the contributions of all the variables were comparatively low. These findings implied that the key challenges and considerations for practitioners about the abovementioned purposes.

It is to be noticed that the collaboration between Facebook Status Updates and the behavioral circumstances, will be looked at by this study thus providing a basis for future researches as well. In interpreting the results of the study, a few limitations should be born in mind. The limitations also suggest possible direction for future researchers. As a one limitation, although this study has identified three motives (validity, self-expression and communication) for using Facebook on Facebook status updates there are many other important factors to be considered.

Further the sample size of the study is relatively small with compared to the population. Considering the above methodological aspects this study can use more Facebook users in order to ensure a more reliable generalization of the result.

And future researchers can used advance analytical tools like, Structural Equation Modelling (SEM), Chi-Square difference test to analyze data and provide new knowledge to the existing body of knowledge. Furthermore, time duration was a major limitation of current study. Therefore, it is suggested to take considerable time to conduct the study to get generalized conclusions.

In conclusion, the present research demonstrates that there is an impact of validity, selfexpression and communication as motives for using Facebook on Facebook status updates. Furthermore, it can be argued that openness to experience and extraversion are wakening the relationship between motives for using Facebook and Facebook status updates. 
DOI: http://10.4038/kjm.v7i1.7554

\section{References}

Amichai-Hamburger, Y., \& Vinitzky, G. (2010). Social network use and personality. Computers in human behavior, 26(6), 1289-1295. https://doi.org/10.1016/j.chb.2010.03.018

Barrick, M. R., \& Mount, M. K. (1991). The big five personality dimensions and job performance: a meta-analysis. Personnel psychology, 44(1), 1-26. https://doi.org/10.1111/j.1744$\underline{6570.1991 . t b 00688 . x}$

Bazarova, N. N., \& Choi, Y. H. (2014). Self-disclosure in social media: Extending the functional approach to disclosure motivations and characteristics on social network sites. Journal of Communication, 64(4), 635-657. https://doi.org/10.1111/jcom.12106

Bergman, P., Parise, B., Liseau, R., Larsson, B., Olofsson, H., Menten, K. M., \& Güsten, R. (2011). Detection of interstellar hydrogen peroxide. Astronomy \& Astrophysics, 531, L8. https://doi.org/10.1051/0004-6361/201117170

Butt, S., \& Phillips, J. G. (2008). Personality and self-reported mobile phone use. Computers in Human Behavior, 24(2), 346-360. https://doi.org/10.1016/j.chb.2007.01.019

Carr, C. T., Schrock, D. B., \& Dauterman, P. (2012). Speech acts within Facebook status messages. Journal of Language and Social Psychology, 31(2), 176-196. https://doi.org/10.1177/0261927X12438535

Correa, T., Hinsley, A. W., \& De Zuniga, H. G. (2010). Who interacts on the Web?: The intersection of users' personality and social media use. Computers in Human Behavior, 26(2), 247-253. https://doi.org/10.1016/j.chb.2009.09.003

Ellison, N. B., Steinfield, C., \& Lampe, C. (2007). The benefits of Facebook "friends:" Social capital and college students' use of online social network sites. Journal of ComputerMediated Communication, 12(4), 1143-1168. https://doi.org/10.1111/j.1083$\underline{6101.2007 .00367 . x}$

Ellison, S. L., Patton, D. R., Simard, L., \& McConnachie, A. W. (2007). Clues to the Origin of the Mass-Metallicity Relation: Dependence on Star Formation Rate and Galaxy Size. The Astrophysical Journal Letters, 672(2), L107. https://doi.org/10.1086/527296

Facebook Statistics Directory. (2017, July 20). Retrieved from Social Bakers: https://www.socialbakers.com/statistics/facebook/ 
Gosling, S. D., Augustine, A. A., Vazire, S., Holtzman, N., \& Gaddis, S. (2011). Manifestations of personality in online social networks: Self-reported Facebook-related behaviors and observable profile information. Cyberpsychology, Behavior, and Social Networking, 14(9), 483-488. https://doi.org/10.1089/cyber.2010.0087

Hampton, K., Goulet, L. S., Rainie, L., \& Purcell, K. (2011). Social networking sites and our lives. Pew Internet \& American Life Project, 16, 1-85.

Haythornthwaite, C. (2005). Social networks and Internet connectivity effects. Information, Community \& Society, 8(2), 125-147. https://doi.org/10.1080/13691180500146185

Hughes, D. J., Rowe, M., Batey, M., \& Lee, A. (2012). A tale of two sites: Twitter vs. Facebook and the personality predictors of social media usage. Computers in Human Behavior, 28(2), 561-569. https://doi.org/10.1016/j.chb.2011.11.001

John, O.P., \& Srivastava, S. (1999). The Big Five trait taxonomy: History, measurement, and theoretical perspectives. In L.A. Pervin \& O.P. John (Eds.), Handbook of personality. New York: Guilford Press

Marshall, T. C., Lefringhausen, K., \& Ferenczi, N. (2015). The Big Five, self-esteem, and narcissism as predictors of the topics people write about in Facebook status updates. Personality and Individual Differences, 85, 35-40. https://doi.org/10.1016/j.paid.2015.04.039

Pervin, L. A., \& John, O. P. (Eds.). (1999). Handbook of personality: Theory and research. Elsevier.

Ross, C., Orr, E. S., Sisic, M., Arseneault, J. M., Simmering, M. G., \& Orr, R. R. (2009). Personality and motivations associated with Facebook use. Computers in human behavior, 25(2), 578-586. https://doi.org/10.1016/j.chb.2008.12.024

Ryan, T., \& Xenos, S. (2011). Who uses Facebook? An investigation into the relationship between the Big Five, shyness, narcissism, loneliness, and Facebook usage. Computers in Human Behavior, 27(5), 1658-1664. https://doi.org/10.1016/j.chb.2011.02.004

Seidman, I. (2013). Interviewing as qualitative research: A guide for researchers in education and the social sciences. Teachers college press. 
Tong, S. T., Van Der Heide, B., Langwell, L., \& Walther, J. B. (2008). Too much of a good thing? The relationship between number of friends and interpersonal impressions on Facebook. Journal of Computer-Mediated Communication, 13(3), 531-549. https://doi.org/10.1111/j.1083-6101.2008.00409.x

Tosun, L. P., \& Lajunen, T. (2009). Why do young adults develop a passion for Internet activities? The associations among personality, revealing "true self" on the Internet, and passion for the Internet. CyberPsychology \& Behavior, 12(4), 401-406. https://doi.org/10.1089/cpb.2009.0006

Vazire, S., Naumann, L. P., Rentfrow, P. J., \& Gosling, S. D. (2008). Portrait of a narcissist: Manifestations of narcissism in physical appearance. Journal of Research in Personality, 42(6), 1439-1447. https://doi.org/10.1016/j.jrp.2008.06.007

Vitak, J., Zube, P., Smock, A., Carr, C. T., Ellison, N., \& Lampe, C. (2011). It's complicated: Facebook users' political participation in the 2008 election. CyberPsychology, behavior, and social networking, 14(3), 107-114. https://doi.org/10.1089/cyber.2009.0226

Wilson, A., Zeithaml, V. A., Bitner, M. J., \& Gremler, D. D. (2012). Services marketing: Integrating customer focus across the firm. McGraw Hill.

Winter, S., Neubaum, G., Eimler, S. C., Gordon, V., Theil, J., Herrmann, J., \& Krämer, N. C. (2014). Another brick in the Facebook wall-How personality traits relate to the content of status updates. Computers in Human Behavior, 34, 194-202. https://doi.org/10.1016/j.chb.2014.01.048

Zywica, J., \& Danowski, J. (2008). The faces of Facebookers: Investigating social enhancement and social compensation hypotheses; predicting Facebook ${ }^{\mathrm{TM}}$ and offline popularity from sociability and self-esteem, and mapping the meanings of popularity with semantic networks. Journal of Computer-Mediated Communication, 14(1), 1-34. https://doi.org/10.1111/j.1083-6101.2008.01429.x 